\title{
Local Recurrence and Disease-Free Survival After Transanal Total Mesorectal Excision: Results From the International TaTME Registry
}

\author{
Sapho X. Roodbeen, $\mathrm{MD}^{1}$; Marta Penna, MBBS, MRCS${ }^{2}$; Susan van Dieren, $\mathrm{PhD}^{3}$; Brendan Moran, MD, FRCS \\ Paris Tekkis, MD (Lon), HonD, FRCS 5 ; Pieter J. Tanis, MD, PhD¹; and Roel Hompes, MD, PhD'; \\ on behalf of the International TaTME Registry Collaborative*
}

\begin{abstract}
Background: The oncologic safety of transanal total mesorectal excision (TaTME) for rectal cancer has recently been questioned, with high local recurrence (LR) rates reported in Dutch and Norwegian experiences. The objective of this study was to evaluate the oncologic safety of TaTME in a large cohort of patients with primary rectal cancer, primarily in terms of LR, disease-free survival (DFS), and overall survival (OS). Patients and Methods: This was a prospective international registry cohort study, including all patients who underwent TaTME for primary rectal adenocarcinoma from February 2010 through December 2018. The main endpoints were 2-year LR rate, pattern of $L R$, and independent risk factors for LR. Secondary endpoints included 2-year DFS and OS rates. Kaplan-Meier survival analysis was used to calculate actuarial LR, DFS, and OS rates. Results: A total of 2,803 patients receiving primary TaTME were included, predominantly men (71\%) with a median age of 65 years (interquartile ratio, 57-73 years). After a median followup of 24 months (interquartile ratio, 12-38 months), the 2-year LR rate was $4.8 \%(95 \% \mathrm{Cl}, 3.8 \%-5.8 \%)$ with a unifocal LR pattern in 99 of 103 patients $(96 \%)$. Independent risk factors for LR were male sex, threatened resection margin on baseline MRI, pathologic stage III cancer, and a positive circumferential resection margin on final histopathology. The 2-year DFS and OS rates were $77 \%(95 \% \mathrm{Cl}, 75 \%-79 \%)$ and $92 \%$ (95\% Cl, 91\%-93\%), respectively. Conclusions: This largest TaTME cohort to date supports the oncologic safety of the TaTME technique for rectal cancer in patients treated in units that contributed to an international registry, with an acceptable 2-year LR rate and a predominantly unifocal LR pattern.
\end{abstract}

J Natl Compr Canc Netw 2021;19(11):1232-1240 doi: 10.6004/jnccn.2021.7012

See JNCCN.org for supplemental online content.

\section{Background}

Surgery for rectal cancer, based on total mesorectal excision (TME) principles, ${ }^{1}$ remains a challenging procedure, irrespective of the surgical approach. The difficulties of anatomic access to the depths of the pelvis affect the surgeon's ability to achieve a meticulous cancer dissection. This may impair oncologic outcomes, particularly for locally advanced lower rectal cancer in male patients. ${ }^{2-4}$ A laparoscopic rectal cancer operation results in shortterm patient benefits, although widespread adoption of laparoscopic rectal excision remains low and oncologic benefit compared with open surgery was not proven in 2 recent randomized controlled trials., ${ }^{5,6}$ The clinical need to mitigate and overcome challenges in rectal cancer surgery, together with surgical innovation, have led to the development of transanal total mesorectal excision (TaTME). This technique was first performed in a live patient in 2009 and has been adopted in numerous centers globally. ${ }^{7}$

The addition of a transanal phase to a purely abdominal TME approach was hypothesized to improve visualization and optimize dissection, particularly in low rectal cancer, improving the quality of the TME specimen. It

\footnotetext{
${ }^{1}$ Department of Surgery, Amsterdam University Medical Centers, University of Amsterdam, Cancer Center Amsterdam, Amsterdam, the Netherlands;

${ }^{2}$ Department of Colorectal Surgery, Churchill Hospital, Oxford University Hospital NHS Foundation Trust, Oxford, United Kingdom; ${ }^{3}$ Department of Surgery and Clinical Epidemiology, Amsterdam University Medical Centers, University of Amsterdam, Cancer Center Amsterdam, Amsterdam, the Netherlands; ${ }^{4}$ Department of Surgery, Hampshire Hospitals NHS Foundation Trust, Basingstoke, United Kingdom; and ${ }^{5}$ Department of Colorectal Surgery, The Royal Marsden Hospital, Imperial College London, London, United Kingdom.
}

*Members of the International TaTME Registry Collaborative are listed in supplemental eAppendix 1 (available with this article at JNCCN.org).

See page 1320 for related commentary. 
was thought to optimize oncologic outcomes and in particular lead to a reduction in local recurrence (LR) rates. ${ }^{8}$ Histopathologic results for TaTME have been favorable in many reported studies, ${ }^{9-11}$ but the exact role and benefits of TaTME in rectal cancer have recently been challenged. ${ }^{12,13}$ Contemporary publications on the learning curve data from Dutch and Norwegian multicenter datasets have reported high LR rates (up to $12 \%$ ) with a predominantly multifocal LR pattern, which has heightened the controversy. ${ }^{14,15}$ These outcomes are at variance with reports from cohort series by early adopters of the technique and publications from expert centers. ${ }^{16-19}$ From an oncologic perspective, overall survival (OS) and disease-free survival (DFS) are the key outcomes of TaTME, but LR remains a very important outcome after rectal cancer surgery, which can result in major morbidity and poor outcomes.

Careful assessment of the site, rate, and pattern of LR in large datasets provides necessary oncologic quality control of novel operative techniques. For these reasons, the international TaTME registry was initiated to provide data on procedural safety, efficacy, ${ }^{10,20}$ and long-term oncologic safety. The evaluation of disease recurrence rates after TaTME from a large dataset of patients treated for rectal cancer can contribute to the paucity of information currently available and may help address some of the recent controversy in the published literature on oncologic outcomes after TaTME.

The purpose of this prospective report from the international TaTME registry was to evaluate the oncologic outcomes in patients who underwent TaTME for primary rectal cancer, focusing primarily on the rate and pattern of LR in addition to OS and DFS.

\section{Methods}

\section{Patient Selection and Study Design}

Prospective registry-based data were analyzed. The international TaTME registry ${ }^{21}$ is a secure online voluntary database where surgeons from 203 centers worldwide provide data on their patients who undergo TaTME. Ethical approval for the registry was granted by the UK Health Research Authority and Research Ethics Committee (REC reference 15/LO/0499, IRAS project identification 156930).

The registry is designed to prospectively collect data on patient demographics, tumor staging and neoadjuvant therapy (NAT), operative details, postoperative clinical and histologic outcomes, readmission details, late morbidity, and long-term oncologic follow-up. ${ }^{22}$ Before data extraction and analysis, collaborating centers were contacted individually to update oncologic surveillance, with subsequent reminders throughout 2019, to optimize data completeness. Data analysis and extraction were performed in February 2020. The dataset was updated, and surgeons were contacted individually to clarify results.
All records with an operation date before January 1, 2019, were reviewed to allow for a minimum follow-up period of 1 year. Centers were excluded if $>10 \%$ of their patient records had $\geq 1$ missing values for the main outcome parameters; we considered these centers as not having their data accurately reported. Other exclusion criteria were benign disease, previous completion TaTME (ie, previous local excision of a malignant polyp or early rectal cancer), rectal cancer $>10 \mathrm{~cm}$ from the anorectal junction (ARJ), locally recurrent rectal cancer, palliative procedures, and any pathologic diagnosis other than adenocarcinoma on final histopathology.

\section{Outcome Parameters}

The primary outcome of this study was the 2-year LR rate. Secondary endpoints were the pattern of LR (whether unifocal or multicentric), independent risk factors for LR, and 2-year DFS and OS rates.

DFS was defined as patients who were alive without evidence of local or distant recurrence. OS was defined as those who were alive with or without cancer at the end of follow-up. With regard to histopathologic details, nonradical resection margin status was defined as the presence of a tumor or malignant lymph nodes at or within $1 \mathrm{~mm}$ of the circumferential resection margin (CRM) and/or distal resection margin (DRM) of the specimen. The optimal pathologic outcome was defined as a composite of clear resection margin status, complete or nearly complete TME specimen, and no rectal perforation. The TME specimen quality was categorized as outlined by Nagtegaal et al. ${ }^{8}$ TNM stages I-IV were defined as follows: stage I: pT0-2pNOM0; stage II: pT3-4pN0M0; stage 3: pT0-4pN1-2cM0; and stage IV: pT0-4pN0-2cM1.

\section{Statistical Analysis}

All categorical data are presented as the number of patients and percentages, and continuous data are shown as median and interquartile range (IQR). Missing data did not exceed $15 \%$ for each variable, and percentages shown represent the data available, excluding missing values. Independent risk factors were identified by univariable and multivariable Cox regression analysis. Factors with a $P$ value $<.10$ in univariable analysis were entered into multivariable Cox regression analysis. Factors showing a $P$ value $<.05$ were considered significant and therefore predisposed for LR, presented as odds ratios (ORs) and 95\% confidence intervals. Kaplan-Meier analysis was used to determine the actuarial cumulative proportion of LR, DFS, and OS rates at 2 years from the date of surgery, censored for the patients not reaching the follow-up timepoint. Regarding DFS, patients with LR or distant metastasis or death at 2 years were included as an event. TNM stages I-IV of disease, based on the 8th 


\section{Table 1. Patient and Tumor Characteristics}

\begin{tabular}{|c|c|}
\hline Characteristic & n (\%) \\
\hline Male sex & $1,991 / 2,803(71.0)$ \\
\hline Age, median (IQR), y & $65(57-73)$ \\
\hline $\mathrm{ASA} \geq 3$ & $640 / 2,760(23.2)$ \\
\hline $\mathrm{BMI}$, median (IQR), kg/m² & $25.8(23.3-28.9)$ \\
\hline$\geq 30$ & $504 / 2,708(18.6)$ \\
\hline Tumor height from ARJ, median (IQR), cm & $4(2-6)$ \\
\hline$\leq 1 \mathrm{~cm}$ & $583 / 2,778(21.0)$ \\
\hline Anterior and/or circumferential tumor & $1,211 / 2,431(49.8)$ \\
\hline MRI performed & $2,614 / 2,803(93.3)$ \\
\hline \multicolumn{2}{|l|}{ cT stage on baseline MRI } \\
\hline $\mathrm{T} 1$ & $75 / 2,442(3.1)$ \\
\hline $\mathrm{T} 2$ & 620/2,442 (25.4) \\
\hline T3 & $1,544 / 2,442(63.2)$ \\
\hline T4 & $176 / 2,442(7.2)$ \\
\hline$T x$ & $27 / 2,442(1.1)$ \\
\hline \multicolumn{2}{|l|}{ cN stage on baseline MRI } \\
\hline No & $1,043 / 2,570(40.6)$ \\
\hline N1 & $1,047 / 2,570(40.7)$ \\
\hline N2 & $446 / 2,570(17.4)$ \\
\hline $\mathrm{Nx}$ & $34 / 2,570(1.3)$ \\
\hline cM1 stage & $231 / 2,750(8.4)$ \\
\hline Threatened MRF on baseline MRI & $654 / 2,377(27.5)$ \\
\hline \multicolumn{2}{|l|}{ EMVI on baseline MRI } \\
\hline Positive & $304 / 1,126(26.9)$ \\
\hline Not reported/missing & $1,677 / 2,803(56.9)$ \\
\hline Received NAT & $1,746 / 2,803(62.3)$ \\
\hline SC-RT_immediate surgery & $151 / 2,803(5.4)$ \\
\hline SC-RT_delayed surgery & $71 / 2,803(2.5)$ \\
\hline LC-RT & $116 / 2,803(4.1)$ \\
\hline CRT & $1,313 / 2,803(46.8)$ \\
\hline Chemotherapy only & $56 / 2,803(2.0)$ \\
\hline Contact RT & $3 / 2,803(0.1)$ \\
\hline
\end{tabular}

(continued)

edition of the Union for International Cancer Control TNM classification, ${ }^{23}$ were compared using Kaplan-Meier analysis. Data were analyzed using SPSS Statistics, version 25.0 (IBM Corp).

\section{Results}

A total of 4,108 patients registered in the database underwent a TaTME for a malignant indication between February 2010 and December 2018. Of these patients, 2,803 were included as presented in supplemental eFigure 1 (available with this article at JNCCN.org). The remainder were excluded because 227 had completion TaTMEs; 66

\section{Table 1. Patient and Tumor Characteristics (cont.)}

\begin{tabular}{|c|c|}
\hline Characteristic & n (\%) \\
\hline \multicolumn{2}{|c|}{ mTRG response on restaging after downsizing $N A T^{a}$} \\
\hline mTRG $1 / 2$ (good response) & $493 / 1,082(45.6)$ \\
\hline mTRG 3 (intermediate response) & $359 / 1,082(33.2)$ \\
\hline mTRG 4/5 (poor response) & $230 / 1,082(21.2)$ \\
\hline Not reported/missing & $510 / 1,592(32.0)$ \\
\hline \multicolumn{2}{|l|}{ Anastomotic technique } \\
\hline Stapled & $1,763 / 2,470(71.4)$ \\
\hline Manual & $707 / 2,470(28.6)$ \\
\hline \multicolumn{2}{|l|}{ If stapled } \\
\hline E-E & $994 / 1,763(56.4)$ \\
\hline S-E & $761 / 1,763(43.2)$ \\
\hline IPAA & $8 / 1,763(0.5)$ \\
\hline \multicolumn{2}{|l|}{ If manual } \\
\hline E-E & $461 / 707(65.2)$ \\
\hline S-E & $217 / 707(30.7)$ \\
\hline IPAA & 9/707 (1.3) \\
\hline Colonic J-pouch & 20/707 (2.8) \\
\hline
\end{tabular}

Abbreviations: ASA, American Society of Anesthesiologists classification; ARJ, anorectal junction; BMI, body mass index; $\mathrm{CM} 1$ stage, clinical metastatic stage; $\mathrm{CN}$ stage, clinical nodal stage; CRT, chemoradiotherapy; cT stage, clinical tumor stage; EMVI, extramural vascular invasion; IQR, interquartile range; LC-RT, long-course radiotherapy; MRF, mesorectal fascia (defined as threatened if the distance of tumor or malignant lymph node to the mesorectal fascia was $\leq 1 \mathrm{~mm}$ ); mTRG, tumor regression grade on restaging MRI; NAT, neoadjuvant therapy; RT, radiotherapy; SC-RT, short-course radiotherapy. ${ }^{a}$ mTRG was only given for patients who received downsizing NAT. Downsizing NAT was considered because all types of NAT exclude SC-RT, immediate surgery, and contact $R T(N=1,592[1,746-154])$.

had tumors $>10 \mathrm{~cm}$ from the ARJ; 51 had local recurrence, palliative procedures, or diagnosis other than adenocarcinoma on final histopathology; and 1,001 were treated in centers where $>10 \%$ of their cases had $\geq 1$ missing values for the main outcome parameters. Patient and tumor characteristics are outlined in Table 1. Overall, $71 \%$ of the 2,803 patients were male, and the mean age of the cohort was 65 years (IQR, 57-73 years). Median tumor height from the ARJ was $4 \mathrm{~cm}$ (IQR, 2-6 $\mathrm{cm})$. Half of the patients had anterior tumors, and the mesorectal fascia was threatened in $28 \%$ of patients on the staging MRI scan. Approximately two-thirds of patients received some form of NAT. After NAT, good tumor regression grade was reported in $46 \%$ of patients. A low anterior resection was performed in most patients (91\%). Complete details on intraoperative and postoperative characteristics are provided in supplemental eTable 1.

\section{Histopathologic Outcomes}

Histopathologic outcomes are shown in Table 2. A complete TME was achieved in $86 \%$ of patients, whereas 
major defects of the mesorectum were found in $3 \%$. An incomplete resection (nonradical resection margin) was reported in $7 \%$ of patients, after excluding the patients with a complete pathologic response (ypT0N0). The CRM was positive $(\mathrm{CRM}+)$ in $5.1 \%$ of patients, the DRM was involved $(\mathrm{DRM}+)$ in $1.0 \%$ of patients, and a combination of both CRM+/DRM+ was found in $0.7 \%$. A higher rate of DRM+ $(5 \%$ vs $0.9 \% ; P<.001)$ and $\mathrm{CRM}+(3.7 \%$ vs $1.9 \% ; P<.001)$ was observed in patients with low tumors $(<1 \mathrm{~cm}$ from the ARJ). In $1.6 \%$ of patients, a rectal perforation at the time of surgery occurred. An optimal pathologic outcome was achieved in $90 \%$ of patients.

\section{Local Recurrence}

After a median follow-up of 24 months (IQR, 12-38 months), the actuarial 2-year LR rate was $4.8 \%$ (95\% CI, $3.8 \%-5.8 \%$ ) (Table 3, Figure 1A). This rate varied from $1.9 \%$ (95\% CI, $0.9 \%-3.0 \%$ ) for patients with TNM stage I disease up to $11.1 \%$ (95\% CI, $6.1 \%-16.0 \%$ ) for patients with TNM stage IV disease (Figure 1B). Median time to detection of LR was 14 months (IQR, 9-24 months). LR was mostly located in the presacral space $(30 \%)$, at the anastomotic site $(25 \%)$, or in the lateral pelvic side wall (23\%). A multifocal pattern was reported in $4 \%$ of patients. LR was diagnosed in 73 of 122 (60\%) of patients without any metastatic disease, 48 of whom (66\%) had salvage surgery.

Independent risk factors for LR in multivariate Cox regression analysis were male sex $(\mathrm{OR}, 1.6 ; 95 \% \mathrm{CI}$, $1.1-2.5 ; P=.029)$, a threatened mesorectal fascia on baseline MRI (OR, 1.5; 95\% CI, 1.1-2.3; $P=.024)$, (y)pN1-2 stage disease (OR, 2.1; 95\% CI, 1.5-3.0; $P<.001)$, and $\mathrm{CRM}+$ on final histopathology (pCRM +; OR, 2.3; 95\% CI, 1.3-3.9; $P=.004$ ) (Table 4). Other pathologic outcomes, such as TME quality, rectal perforation, and DRM+, were significantly associated with LR on univariate analysis but not on multivariate analysis.

\section{Survival}

The 2-year actuarial DFS was $76.6 \% \quad(95 \% \quad \mathrm{CI}$, $74.7 \%-78.5 \%)$. This rate varied from $89.2 \%$ (95\% CI, $86.8 \%-91.6 \%)$ for patients with TNM stage I disease to $33.6 \%$ (95\% CI, $26.2 \%-41.1 \%$ ) for those with TNM stage IV disease (Figure 1C, D). The 2-year actuarial OS was 91.9\% (95\% CI, 90.7\%-93.2\%). This rate ranged from 96.1\% (95\% CI, 94.7\%-97.5\%) for patients with TNM stage I disease to $72.3 \%$ (95\% CI, $65.1 \%-79.5 \%$ ) for those with TNM stage IV disease (Figure 1E, F).

\section{Discussion}

In this largest cohort to date of patients who had a TaTME for rectal cancer who were registered in a prospective international registry, the 2-year LR rate was $5 \%$. LRs were generally unifocal, with few multifocal LR

\begin{tabular}{|c|c|}
\hline Outcome & n (\%) \\
\hline \multicolumn{2}{|l|}{ (y)pT stage } \\
\hline TO & $304 / 2,767(11.0)$ \\
\hline T1 & $293 / 2,767(10.6)$ \\
\hline $\mathrm{T} 2$ & $872 / 2,767(31.5)$ \\
\hline T3 & $1,213 / 2,767(43.8)$ \\
\hline T4 & $77 / 2,767(2.8)$ \\
\hline Tx & $8 / 2,767(0.3)$ \\
\hline \multicolumn{2}{|l|}{ (y)pN stage } \\
\hline NO & $1,886 / 2,764(68.2)$ \\
\hline N1 & $586 / 2,764(21.2)$ \\
\hline N2 & $281 / 2,764(10.2)$ \\
\hline $\mathrm{Nx}$ & $11 / 2,764(0.4)$ \\
\hline No residual tumor and nodes & $279 / 2,767(10.1)$ \\
\hline \multicolumn{2}{|l|}{ pEMVI } \\
\hline Positive & $254 / 1,293(19.6)$ \\
\hline Not reported/missing & $1,510 / 2,803(53.9)$ \\
\hline \multicolumn{2}{|l|}{ TME specimen } \\
\hline Complete & $2,280 / 2,644(86.2)$ \\
\hline Nearly complete & $285 / 2,644(10.8)$ \\
\hline Incomplete & $79 / 2,644(3.0)$ \\
\hline R1 (excluding no residual tumor and nodes) & $170 / 2,469(6.9)$ \\
\hline Only DRM+ & $25 / 2,469(1.0)$ \\
\hline Only CRM+ & $125 / 2,469(5.1)$ \\
\hline $\mathrm{DRM}+$ and $\mathrm{CRM}+$ & $17 / 2,469(0.7)$ \\
\hline Unknown & $3 / 2,469(0.1)$ \\
\hline Rectal perforations & $41 / 2,624(1.6)$ \\
\hline Composite optimal pathology ${ }^{a}$ & $2,303 / 2,568(89.7)$ \\
\hline
\end{tabular}

Percentages for the variables were calculated from the total number of actual results available, excluding missing values.

Abbreviations: CRM+, positive circumferential resection margin; CRMnegative circumferential resection margin; $\mathrm{DRM}+$, positive distal resection margin; DRM-, negative distal resection margin; pEMVI, pathologic extramural vascular invasion; R1, nonradical resection margin (defined as tumor or malignant lymph nodes at or within $1 \mathrm{~mm}$ from the resection plane); TME specimen, total mesorectal excision specimen; $(\mathrm{y}) \mathrm{pN}$ stage, pathologic nodal stage; (y)pT stage, pathologic tumor stage.

${ }^{a}$ Composite optimal pathology: CRM- and DRM- and complete or nearly complete TME specimen and no perforations.

presentations at a median follow-up period of 2 years. These findings are in contrast to data from a Norwegian national audit, with an estimated LR rate at 2.4 years of $11.6 \%$ and a multifocal or extensive pattern of LR in two-thirds of the patients. ${ }^{15}$ Similarly, poor results were reported in a Dutch study that looked at the implementation of TaTME in a national training program. ${ }^{14}$ In the first 10 patients reviewed from 12 centers, a crude LR rate of $10 \%$ was reported with a similar pattern of multifocal recurrence in 8 of 12 patients with LR. 


\section{Table 3. Oncologic Outcomes}

\begin{tabular}{|c|c|}
\hline Outcome & n (\%) \\
\hline Follow-up, median (IQR), mo & $24(12-38)$ \\
\hline Adjuvant treatment & $1,146 / 2,564(44.7)$ \\
\hline 2 -year LR $(95 \% \mathrm{Cl})^{\mathrm{a}}$ & $4.8(3.8-5.8)$ \\
\hline TNM stage I & $1.9(0.9-3.0)$ \\
\hline TNM stage II & $3.9(2.1-5.8)$ \\
\hline TNM stage III & $8.2(5.5-10.9)$ \\
\hline TNM stage IV & $11.1(6.1-16.0)$ \\
\hline Time to $L R$, median (IQR), mo & $14(9-24)$ \\
\hline Location of LR & $101 / 122$ \\
\hline Anterior & $11 / 103(10.7)$ \\
\hline Presacral & $31 / 103(30.1)$ \\
\hline Inferior & 4/103 (3.9) \\
\hline Lateral (pelvic sidewall) & 24/103 (23.3) \\
\hline Central & $3 / 103(2.9)$ \\
\hline Anastomotic & 26/103 (25.2) \\
\hline Multifocal & 4/103 (3.9) \\
\hline Missing & 18/121 (14.9) \\
\hline 2-year DFS $(95 \% \mathrm{Cl})^{a}$ & $76.6(74.7-78.5)$ \\
\hline TNM stage I & $89.2(86.8-91.6)$ \\
\hline TNM stage II & $79.9(76.0-83.8)$ \\
\hline TNM stage III & $66.1(62.1-70.2)$ \\
\hline TNM stage IV & $33.6(26.2-41.1)$ \\
\hline 2 -year OS $(95 \% \mathrm{Cl})^{\mathrm{a}}$ & $91.9(90.7-93.2)$ \\
\hline TNM stage I & $96.1(94.7-97.5)$ \\
\hline TNM stage II & $93.2(90.9-95.4)$ \\
\hline TNM stage III & $89.8(87.0-92.6)$ \\
\hline TNM stage IV & $72.3(65.1-79.5)$ \\
\hline
\end{tabular}

Percentages for the variables were calculated from the total number of actual results available, excluding missing values.

TNM staging is based on the 8th edition of the Union for International Cancer Control TNM classification.

Abbreviations: DFS, disease-free survival; IQR, interquartile range; $L R$, local recurrence; OS, overall survival.

aLR, DFS, and OS rates represent the actuarial rate and were calculated by Kaplan-Meier survival analysis, accounting for patients who did not reach the 2-year follow-up timepoint.

A number of other studies from early adopters of TaTME reported good oncologic outcomes with regard to pelvic recurrence, similar to the findings in this study. Hol et al ${ }^{16}$ published a $2 \% 3$-year LR rate in 159 patients who received TaTME, with no multifocal pattern of LR, and Kang et $\mathrm{al}^{24}$ reported a $6.2 \%$ LR rate after a median follow-up of 35 months in 211 patients who received TaTME. Outcomes on 767 patients from 6 tertiary referral centers were reported by Roodbeen et al, ${ }^{18}$ with a 2 -year LR rate of 3.3\% and no multifocal pattern of LR reported. Similarly, Perdawood et $\mathrm{al}^{17}$ reported a $4.7 \%$ LR rate after 120 TaTME procedures with a multifocal LR pattern in $1.5 \%$. More recently, Simo et $\mathrm{al}^{19}$ published outcomes after 173 TaTME procedures in 10 Chinese centers with an LR rate of $3 \%$ after a median follow-up of 23 months.

Our findings compare favorably with published 2-year LR rates after laparoscopic and open TME. Respectively, the ACOSOG Z6051 and ALaCaRT randomized trials reported LR rates of $4.6 \%$ and $5.4 \%$ for laparoscopic TME and $4.5 \%$ and $3.1 \%$ for open TME. ${ }^{5,6}$ Both trials also used a composite endpoint of pathologic factors indicating adequate surgical resection. In the patients treated using laparoscopic TME in the ACOSOG and ALaCaRT trials, respectively, this was achieved in $81.7 \%$ and $82 \%$, compared with $86.9 \%$ and $89 \%$ of patients after open TME. ${ }^{25,26}$ In our study, this composite endpoint was achieved in $90 \%$ of patients, suggesting more precise surgery compared with the laparoscopic groups in both of the randomized trials and similar results to those for patients treated using open surgery. However, caution is warranted when comparing registry data with randomized controlled trial data given the known limitations of registry-based data collection and analysis. ${ }^{27}$ However, in contrast, the strict inclusion and exclusion criteria in randomized controlled trials may result in difficulties extrapolating data from a selected group to population-based treatments. ${ }^{28}$

Population-based studies reflecting routine rectal cancer surgical practice may be a better benchmark, although long-term outcomes from national audits are limited in detail and somewhat outdated. A Dutch snapshot study included all TME procedures $(n=2,095)$ performed in 2011 and reported a 3-year LR rate of $6 \%$ and a DFS rate of $67 \% .{ }^{29}$ A Norwegian national colorectal audit reported a 5 -year LR rate ranging from $4 \%$ to $5 \%$ for the period 2010 to 2018 in patients with stages I-III rectal cancer. ${ }^{30}$ A Swedish population-based study including 2,318 patients undergoing TME between 1995 and 2003 reported an LR rate of $6 \%{ }^{31} \mathrm{~A}$ Korean study by Yun et al ${ }^{32}$ reported a $6 \%$ LR rate in 2,485 patients after rectal cancer surgery between 1994 and 2008. The LR rate in the present study is in line with the results reported in these large registry-based datasets, suggesting that TaTME results in equivalent or superior local disease control.

The strongest independent risk factor for the development of LR was pCRM+, with an OR of 2.27 (95\% CI, 1.31-3.94). The other individual components of the composite endpoint of optimal pathology, DRM + or a perforated specimen, were significant on univariate analysis but were not independent predictors for LR on multivariate analysis. It has previously been reported that pCRM+ after TME is one of the most important predictors for the development of LR. ${ }^{8}$ It is therefore unsurprising that the Norwegian TaTME national cohort study had a high LR rate given that the CRM + rate was $13 \%{ }^{33}$ This high pCRM+ rate for TaTME and a specimen 
A

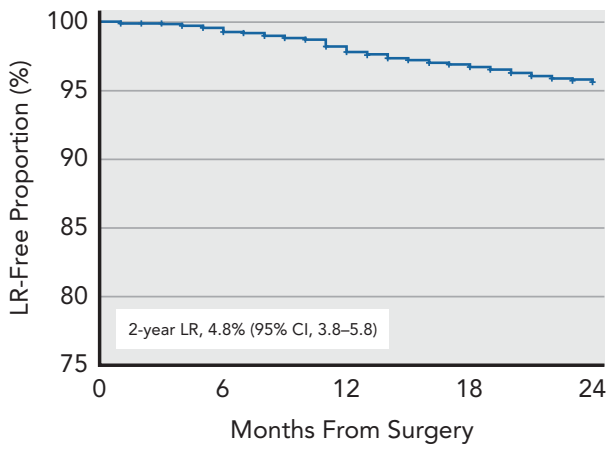

Number at risk

$\begin{array}{llllll}\text { TatME } & 2,796 & 2,491 & 2,124 & 1,759 & 1,400\end{array}$

C

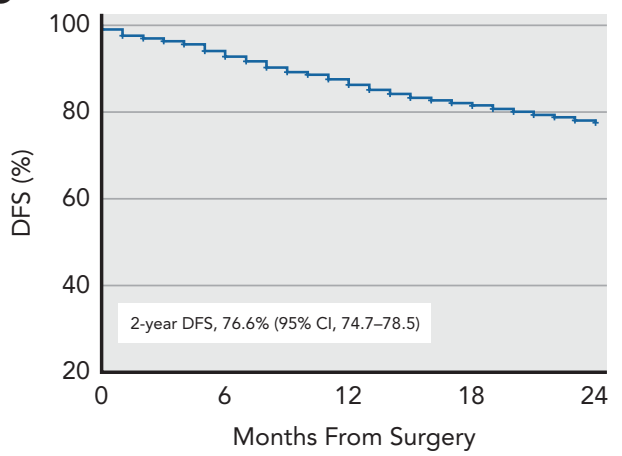

Number at risk

$\begin{array}{llllll}\text { TatME } & 2,796 & 2,418 & 1,974 & 1,704 & 1,243\end{array}$

E

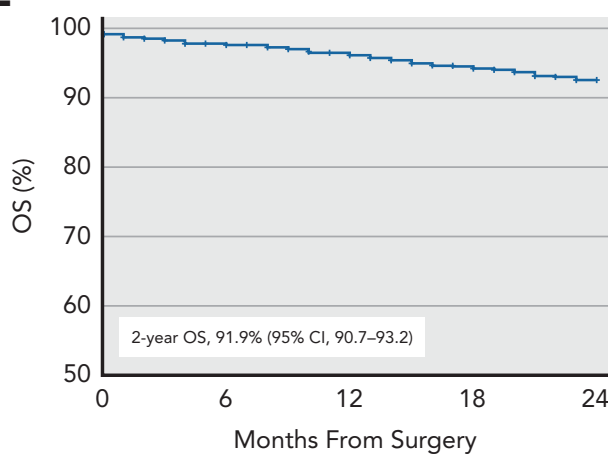

Number at risk

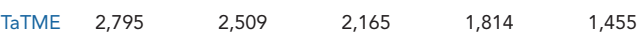

B

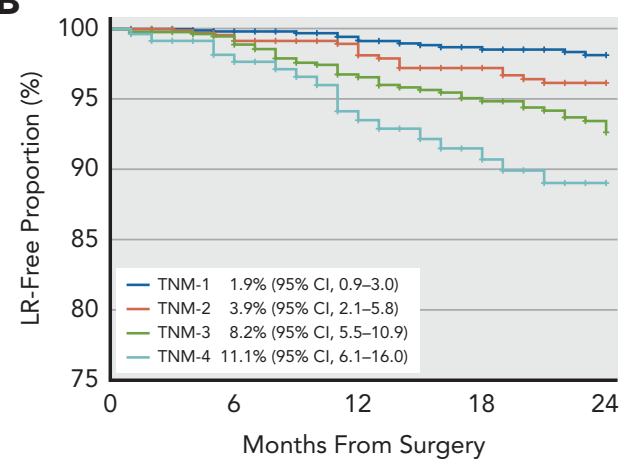

Number at risk

$\begin{array}{rrrrrr}\text { Stage I } & 916 & 826 & 719 & 599 & 748 \\ \text { Stage II } & 607 & 548 & 469 & 389 & 310 \\ \text { Stage III } & 737 & 655 & 554 & 459 & 365 \\ \text { Stage IV } & 230 & 196 & 150 & 131 & 88\end{array}$

D

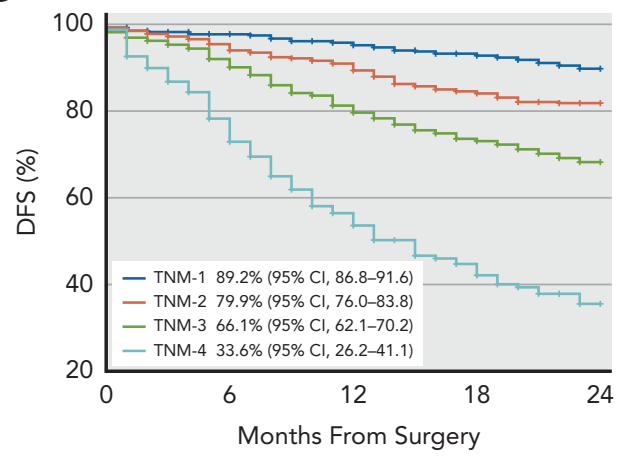

Number at risk

$\begin{array}{rrrrrr}\text { Stage I } & 916 & 823 & 706 & 581 & 454 \\ \text { Stage II } & 607 & 539 & 450 & 363 & 288 \\ \text { Stage III } & 737 & 629 & 490 & 388 & 300 \\ \text { Stage IV } & 230 & 163 & 101 & 68 & 46\end{array}$

$\mathbf{F}$

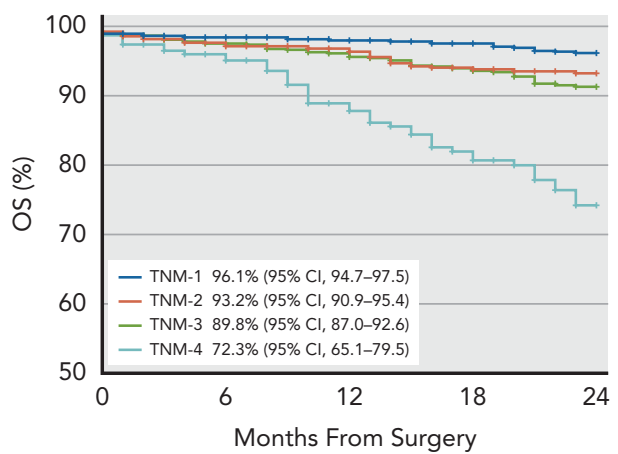

Number at risk

$\begin{array}{rrrrrr}\text { Stage I } & 916 & 828 & 723 & 608 & 486 \\ \text { Stage II } & 607 & 551 & 476 & 399 & 322 \\ \text { Stage III } & 736 & 662 & 574 & 483 & 388 \\ \text { Stage IV } & 230 & 202 & 160 & 129 & 96\end{array}$

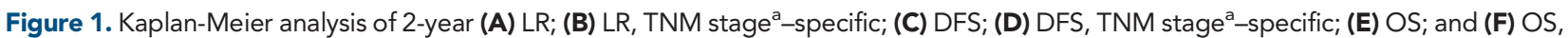
TNM stage ${ }^{\text {a }}$-specific.

Abbreviations: DFS, disease-free survival; LR, local recurrence; OS, overall survival; TaTME, transanal total mesorectal excision.

${ }^{\mathrm{a}}$ Based on the 8th edition of the UICC TNM Classification of Malignant Tumours. 


\begin{tabular}{|c|c|c|c|c|}
\hline Variable & OR $(95 \% \mathrm{Cl})$ & $P$ Value & OR $(95 \% \mathrm{Cl})$ & $P$ Value \\
\hline \multicolumn{5}{|l|}{ Sex (Ref: female) } \\
\hline Male & $1.527(0.996-2.341)$ & .052 & $1.615(1.051-2.484)$ & .029 \\
\hline \multicolumn{5}{|c|}{ BMI, $\mathrm{kg} / \mathrm{m}^{2}$ (Ref: $\left.<30 \mathrm{~kg} / \mathrm{m}^{2}\right)$} \\
\hline \multicolumn{5}{|c|}{ MRF threatened (Ref: no) } \\
\hline Yes & $1.918(1.338-2.749)$ & $<.001$ & $1.544(1.060-2.249)$ & .024 \\
\hline \multicolumn{5}{|c|}{ Distance from ARJ (Ref: $>1 \mathrm{~cm}$ ) } \\
\hline$\leq 1 \mathrm{~cm}$ & $1.434(0.904-2.276)$ & .126 & & \\
\hline \multicolumn{5}{|c|}{ Anterior tumor (Ref: no) } \\
\hline \multicolumn{5}{|l|}{ APE (Ref: no) } \\
\hline Yes & $1.137(0.596-2.172)$ & .696 & & \\
\hline \multicolumn{5}{|c|}{ Abdominal approach (Ref: MIS) } \\
\hline Open & $2.792(1.030-7.570)$ & .044 & $2.397(0.872-6.587)$ & .090 \\
\hline \multicolumn{5}{|c|}{ Adverse event (intraoperative) (Ref: no) } \\
\hline Yes & $1.093(0.637-1.877)$ & .746 & & \\
\hline \multicolumn{5}{|c|}{ Tumor stage (Ref: (y)pT0-3) } \\
\hline (y)pT4 & $2.762(1.348-5.660)$ & .005 & $1.442(0.667-3.116)$ & .352 \\
\hline \multicolumn{5}{|c|}{ Nodal stage (Ref: (y)pN0) } \\
\hline $\mathrm{CRM}+$ & $3.831(2.370-6.194)$ & $<.001$ & $2.268(1.306-3.937)$ & .004 \\
\hline \multicolumn{5}{|c|}{ DRM status (Ref: DRM-) } \\
\hline $\mathrm{DRM}+$ & $3.290(1.447-7.480)$ & .004 & $1.985(0.835-4.720)$ & .121 \\
\hline
\end{tabular}

Bold indicates statistically significant $P$ values.

After single imputation of BMI, MRF threatened, tumor height from ARJ, anterior tumor, NAT, APE, abdominal approach, (y)pT-4 stage, (y)pN1-2 stage, rectal perforation, TME quality, and CRM and DRM status.

Abbreviations: APE, abdominoperineal excision; ARJ, anorectal junction; BMI, body mass index; CRM, circumferential resection margin; CRM+, positive circumferential resection margin; CRM-, negative circumferential resection margin; DRM, distal resection margin; DRM+, positive distal resection margin;

DRM-, negative distal resection margin; MIS, minimally invasive surgery; MRF, mesorectal fascia; NAT, neoadjuvant therapy; TME, total mesorectal excision; (y)pN stage, pathologic nodal stage; (y)pT stage, pathologic tumor stage.

perforation rate of $4.4 \%$ suggest suboptimal surgery in that national cohort.

However, the high LR rate of $10 \%$ in the Dutch TaTME cohort $^{14}$ is difficult to explain given the low pCRM + rate of 5\%. Moreover, pathologic CRM positivity does not provide an explanation for the multifocal pattern of LR in either recent report. ${ }^{14,33}$ There are features of the TaTME technique that may account for the noted multifocal pelvic recurrence, such as tumor spillage when the transanal purse string fails, or omitting rectal washout together with high insufflation pressures, which could enhance multifocal implantation of viable malignant cells. Detailed analysis of TaTME operations, perhaps through systematic video analysis, could help evaluate this hypothesis. Furthermore, data from the Dutch cohort suggest that multifocal LR may be a consequence of technical problems early in the learning curve of surgeons. In the expanded Dutch cohort of 266 
patients, the overall LR rate was $5.6 \%$ and dropped to $4 \%$ if the first 10 procedures at each center were excluded. ${ }^{14}$ Surprisingly, Dutch surgeons selected patients with a threatened resection margin early on in their experience, suggesting that careful patient selection is a key aspect of the learning curve. This notion is particularly important, given that the current data confirm that these patients have an increased risk of LR.

This prompts the question of whether the widespread and rapid adoption of TaTME was in the best interests of patients. Centralization and high-volume experience may result in more optimal outcomes. A structured TaTME training program incorporating a sufficient caseload under the supervision of an experienced proctor, before independent practice of TaTME, may also address some of the pitfalls. ${ }^{29}$ In addition to strict adherence to oncologic principles, more rigid and structured implementation of TaTME may also reduce perioperative morbidity, and particularly procedure-specific complications, such as urethral injuries.

The current data reveal the low penetrance of the robotic approach to the abdominal phase of TaTME. The transanal phase of a TaTME procedure provides a clear view of the dissection plane low down in the pelvis, thereby limiting the benefit of a robotic approach from above. Omission of the robot to obtain an optimal oncologic TME dissection potentially renders TaTME more cost-effective.

There are limitations in the current study, mainly that the data reported are from a voluntary registry. This source introduces the potential for selection and reporting bias because not all surgeons performing TaTME contributed to the registry, and centers that contributed may not have recorded all patients. In addition, there is currently no formal external validation process for the registry and the accuracy relies on collaborators' probity. We attempted to increase data accuracy by requesting that surgeons update their data on the registry before data extraction, by contacting surgeons individually in situations of unexpected or incongruous data, and by excluding centers with $>10 \%$ of patients with missing outcome variables. In addition, local hospital protocols, including surgical resection details, histopathologic assessment, and oncologic follow-up protocols, may vary between the collaborating centers, thereby reducing quality assurance. Finally, not all relevant factors were accurately reported, such as extramural vascular invasion status, which did not allow extramural vascular invasion to be analyzed in the multivariate model. However, despite these limitations, this registry study provides the largest international TaTME cohort reporting on oncologic outcomes, and includes surgeons and centers at all stages of their learning curve experience.

\section{Conclusions}

Findings from this prospective registry study support the oncologic safety of TaTME in patients undergoing surgery by surgeons participating in the TaTME registry. Our results expand on the paucity of data on oncologic outcomes and address some of the controversies in the published literature on pelvic recurrence rates and patterns of recurrence after TaTME. Future studies should focus on understanding the patterns and mechanisms contributing to development of LR after TaTME. ${ }^{29}$ Definitive answers on the oncologic safety of TaTME compared with laparoscopic TME will be shown in outcomes of the ongoing COLOR III and ETAP-GRECCAR 11 trials. ${ }^{31,34}$ As in all operative procedures for rectal cancer, patient selection, technique, training, and experience are pivotal in optimizing the outcomes of TaTME.

\section{Acknowledgments}

The authors thank all participating centers registered in the TaTME registry for inputting and updating their data. They also thank the Pelican Cancer Foundation and the Oxford Colon Cancer Trust for funding the registry.

Submitted September 20, 2020; final revision received January 21, 2021 ; accepted for publication January 21, 2021

Published online August 17, 2021.

Author contributions: Study concept and design: Roodbeen, Penna, Tanis, Hompes. Provision of study material and patients: International TaTME Registry Collaborative. Data collection and assembly: International TaTME Registry Collaborative, Roodbeen, Penna. Data analysis and interpretation: Roodbeen, Penna, van Dieren, Tanis, Hompes. Manuscript preparation and final approval: All authors.

Disclosures: Dr. Hompes has disclosed receiving an Applied Medical and Conmed honorarium for lectures and TaTME courses. The remaining authors have disclosed that they have not received any financial consideration from any person or organization to support the preparation, analysis, results, or discussion of this article.

Disclaimer: Ethical approval for the TaTME Registry and the publication of its results was obtained from the United Kingdom Health Research Authority and Research Ethics Committee (REC reference 15/LO/0499, IRAS project identification 156930).

Correspondence: Roel Hompes, MD, PhD, Department of Surgery Amsterdam University Medical Centers, University of Amsterdam, Cancer Center Amsterdam, Meibergdreef 9, 1105 AZ Amsterdam, the Netherlands. Email: r.hompes@amsterdamumc.nl

\section{References}

1. Heald RJ, Ryall RD. Recurrence and survival after total mesorectal excision for rectal cancer. Lancet 1986;1:1479-1482.
2. Quirke P, Steele R, Monson J, et al. Effect of the plane of surgery achieved on local recurrence in patients with operable rectal cancer: a 
prospective study using data from the MRC CR07 and NCIC-CTG CO16 randomised clinical trial. Lancet 2009;373:821-828.

3. Rullier E, Denost Q, Vendrely V, et al. Low rectal cancer: classification and standardization of surgery. Dis Colon Rectum 2013;56:560-567.

4. van Gijn W, Marijnen CA, Nagtegaal ID, et al. Preoperative radiotherapy combined with total mesorectal excision for resectable rectal cancer: 12-year follow-up of the multicentre, randomised controlled TME trial. Lancet Oncol 2011;12:575-582.

5. Fleshman J, Branda ME, Sargent DJ, et al. Disease-free survival and local recurrence for laparoscopic resection compared with open resection of stage II to III rectal cancer: follow-up results of the ACOSOG Z6051 randomized controlled trial. Ann Surg 2019;269:589-595.

6. Stevenson ARL, Solomon MJ, Brown CSB, et al. Disease-free survival and local recurrence after laparoscopic-assisted resection or open resection for rectal cancer: the Australasian laparoscopic cancer of the rectum randomized clinical trial. Ann Surg 2019;269:596-602.

7. Sylla P, Rattner DW, Delgado S, et al. NOTES transanal rectal cancer resection using transanal endoscopic microsurgery and laparoscopic assistance. Surg Endosc 2010;24:1205-1210.

8. Nagtegaal ID, van de Velde CJ, van der Worp E, et al. Macroscopic evaluation of rectal cancer resection specimen: clinical significance of the pathologist in quality control. J Clin Oncol 2002;20:1729-1734.

9. Deijen $\mathrm{CL}$, Tsai A, Koedam TW, et al. Clinical outcomes and case volume effect of transanal total mesorectal excision for rectal cancer: a systematic review. Tech Coloproctol 2016;20:811-824.

10. Penna M, Hompes R, Arnold S, et al. Transanal total mesorectal excision: international registry results of the first 720 cases. Ann Surg 2017;266: 111-117.

11. Roodbeen SX, de Lacy FB, van Dieren S, et al. Predictive factors and risk model for positive circumferential resection margin rate after transanal total mesorectal excision in 2653 patients with rectal cancer. Ann Surg 2019;270:884-891.

12. Larsen SG, Pfeffer $\mathrm{F}$, Kørner H. Norwegian moratorium on transanal total mesorectal excision. Br J Surg 2019;106:1120-1121.

13. Gachabayov M, Bergamaschi R. Is taTME delivering? Updates Surg 2019;71:13-15.

14. van Oostendorp SE, Belgers HJ, Bootsma BT, et al. Locoregional recurrences after transanal total mesorectal excision of rectal cancer during implementation. Br J Surg 2020;107:1211-1220.

15. Wasmuth HH, Faerden AE, Myklebust TA, et al. Transanal total mesorectal excision for rectal cancer has been suspended in Norway. Br J Surg 2020;107:121-130.

16. Hol JC, van Oostendorp SE, Tuynman JB, et al. Long-term oncological results after transanal total mesorectal excision for rectal carcinoma. Tech Coloproctol 2019;23:903-911.

17. Perdawood SK, Kroeigaard J, Eriksen M, et al. Transanal total mesorectal excision: the Slagelse experience 2013-2019. Surg Endosc 2021;35:826-836.

18. Roodbeen SX, Spinelli A, Bemelman WA, et al. Local recurrence after transanal total mesorectal excision for rectal cancer: a multicenter cohort study [published online January 14, 2020]. Ann Surg, doi: 10.1097/ SLA.0000000000003757

19. Simo V, Tejedor P, Jimenez LM, et al. Oncological safety of transanal total mesorectal excision (TaTME) for rectal cancer: mid-term results of a prospective multicentre study [published online April 24, 2020]. Surg Endosc, doi.org/10.1007/s00464-020-07579-4

20. Penna $M$, Hompes $R$, Arnold $S$, et al. Incidence and risk factors for anastomotic failure in 1594 patients treated by transanal total mesorectal excision: results from the International TaTME Registry. Ann Surg 2019;269:700-711.

21. Transanal Total Mesorectal Excision International Registry. Transanal total mesorectal excision. Accessed January 29, 2021. Available at: https:// tatme.medicaldata.eu/

22. Hompes R, Arnold S, Warusavitarne J. Towards the safe introduction of transanal total mesorectal excision: the role of a clinical registry. Colorectal Dis 2014;16:498-501.

23. Brierley JD, Gospodarowicz MK, Wittekind C, eds. Union for International Cancer Control TNM Classification of Malignant Tumors, 8th Edition. Oxford, United Kingdom: John Wiley \& Sons, Ltd; 2017.

24. Kang $L$, Chen YG, Zhang H, et al. Transanal total mesorectal excision for rectal cancer: a multicentric cohort study. Gastroenterol Rep (Oxf) 2019;8:36-41.

25. Fleshman J, Branda M, Sargent DJ, et al. Effect of laparoscopic-assisted resection vs open resection of stage II or III rectal cancer on pathologic outcomes: the ACOSOG Z6051 randomized clinical trial. JAMA 2015;314:1346-1355.

26. Stevenson AR, Solomon MJ, Lumley JW, et al. Effect of laparoscopicassisted resection vs open resection on pathological outcomes in rectal cancer: the ALaCaRT randomized clinical trial. JAMA 2015;314:1356-1363.

27. Colditz GA. Overview of the epidemiology methods and applications: strengths and limitations of observational study designs. Crit Rev Food Sci Nutr 2010;50(Suppl 1):10-12.

28. Rothwell PM. External validity of randomised controlled trials: "to whom do the results of this trial apply?" Lancet 2005;365:82-93.

29. TaTME Guidance Group representing the ESCP (European Society of Coloproctology), in collaboration with the ASCRS (American Society of Colon and Rectal Surgeons), ACPGBI (Association of Coloproctology of Great Britain and Ireland), et al. International expert consensus guidance on indications, implementation and quality measures for transanal total mesorectal excision. Colorectal Dis 2020;22:749-755.

30. Kusters M, Marijnen CA, van de Velde CJ, et al. Patterns of local recurrence in rectal cancer: a study of the Dutch TME trial. Eur J Surg Oncol 2010;36:470-476.

31. Deijen $C L$, Velthuis $S$, Tsai $A$, et al. COLOR III: a multicentre randomised clinical trial comparing transanal TME versus laparoscopic TME for mid and low rectal cancer. Surg Endosc 2016;30:3210-3215.

32. Yun JA, Huh JW, Kim HC, et al. Local recurrence after curative resection for rectal carcinoma: the role of surgical resection. Medicine (Baltimore) 2016;95:e3942.

33. Wasmuth $\mathrm{HH}$, Faerden AE, Myklebust TA, et al. Transanal total mesorec tal excision for rectal cancer has been suspended in Norway. Br J Surg 2020;107:121-130.

34. Lelong B, de Chaisemartin $\mathrm{C}$, Meillat $\mathrm{H}$, et al. A multicentre randomised controlled trial to evaluate the efficacy, morbidity and functional outcome of endoscopic transanal proctectomy versus laparoscopic proctectomy for low-lying rectal cancer (ETAP-GRECCAR 11 TRIAL): rationale and design. BMC Cancer 2017;17:253. 
Supplemental online content for:

\section{Local Recurrence and Disease-Free Survival After Transanal Total Mesorectal Excision: Results From the International TaTME Registry}

Sapho X. Roodbeen, MD; Marta Penna, MBBS, MRCS; Susan van Dieren, PhD;

Brendan Moran, MD, FRCS; Paris Tekkis, MD (Lon), HonD, FRCS; Pieter J. Tanis, MD, PhD; and Roel Hompes, MD, PhD; on behalf of the International TaTME Registry Collaborative

J Natl Compr Canc Netw 2021;19(11):1232-1240

eFigure 1: Flow Diagram of Patient Inclusion

eTable 1: Perioperative Details

eAppendix 1: International TaTME Registry Collaborative 


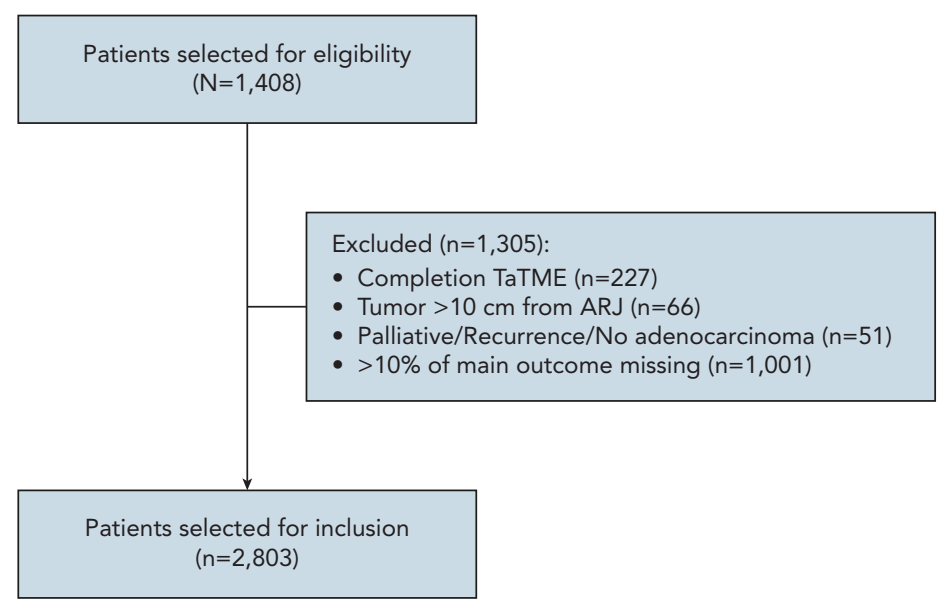

eFigure 1. Flow diagram of patient inclusion.

Abbreviations: ARJ, anorectal junction; TaTME, transanal total mesorectal excision. 
eTable 1. Perioperative Details $(\mathrm{N}=2,803)$

\begin{tabular}{|c|c|}
\hline Perioperative Details & n (\%) \\
\hline \multicolumn{2}{|l|}{ Procedure } \\
\hline LAR & $2,555 / 2,795(91.4)$ \\
\hline APE & $76 / 2,795(2.7)$ \\
\hline isAPE & $131 / 2,795(4.7)$ \\
\hline Proctocolectomy & $26 / 2,795(0.9)$ \\
\hline Other & $7 / 2,795(0.3)$ \\
\hline Anastomosis created & $2,560 / 2,776(92.2)$ \\
\hline Defunctioning stoma (if anastomosis) & $2,188 / 2,497(87.6)$ \\
\hline Two-team procedure & $1,498 / 2,797(53.6)$ \\
\hline Operative time, median (IQR), min & $260(190-326)$ \\
\hline \multicolumn{2}{|l|}{ Abdominal approach } \\
\hline Open & $42 / 2,752(1.5)$ \\
\hline Conventional laparoscopy & $2,451 / 2,752(89.1)$ \\
\hline SILS & $243 / 2,752(8.8)$ \\
\hline Robotic & $16 / 2,752(0.6)$ \\
\hline \multicolumn{2}{|l|}{ Conversion } \\
\hline Abdominal $^{a}$ & $124 / 2,584(4.8)$ \\
\hline Perineal $^{b}$ & $58 / 2,575(2.3)$ \\
\hline Adverse events (intraoperative) & $330 / 2,797(11.8)$ \\
\hline Purse string failure & $70 / 2,797(2.5)$ \\
\hline Bleeding & $135 / 2,797(4.8)$ \\
\hline Incorrect plane & $131 / 2,797(4.7)$ \\
\hline Urethral injury & $20 / 2,797(0.7)$ \\
\hline Other visceral injury & $19 / 2,797(0.7)$ \\
\hline Hospital stay, median (IQR), d & $8(5-13)$ \\
\hline Morbidity $<30 \mathrm{~d}$ & $1,124 / 2,604(43.2)$ \\
\hline \multicolumn{2}{|l|}{ Clavien-Dindo $<30 \mathrm{~d}$} \\
\hline 1 & $264 / 2,604(10.1)$ \\
\hline 2 & $445 / 2,604(17.1)$ \\
\hline 3 & $354 / 2,604(13.6)$ \\
\hline 4 & $33 / 2,604(1.3)$ \\
\hline 5 & $28 / 2,604(1.1)$ \\
\hline
\end{tabular}

Percentages for the variables are calculated from the total number of actual results available, excluding missing values.

Abbreviations: APE, abdominoperineal excision; isAPE, intersphincteric abdominoperineal excision; LAR, anterior resection; SILS, single-incision laparoscopic surgery.

${ }^{a}$ Abdominal conversion was defined as a procedure that was started with the intention to perform a minimally invasive abdominal dissection but required a midline laparotomy.

${ }^{\mathrm{b}}$ Perineal conversion was defined as a change in operative approach from transanal to a more extensive abdominal approach than initially planned. 


\section{eAppendix 1. International TaTME Registry Collaborative (alphabetized by surname)}

Adamina, Michel; Aignerm Felix; Al Furajii, Hazar; Arezzom Alberto; Arnold, Steven J.; Aryal, Kamal; Austin, Ralph; Baekkelund, Oliver; Baloyiannis, loannis; Bandyopadhyay, Dibyendu; Banky, Balazs; Barugola, Giuliano; Basany, Eloy Espin; Belgers, Eric H.J.; Bell, Stephen; Bemelman, Willem; Berti, Stefano; Biebl, Matthias; Bloemendaal, Bobby; Boni, Luigi; Bosker, Robbert J.I.; Box, Benjamin; Brown, Carl; Bruegger, Lukas; Brunner, Walter; Buchli, Christian; Cahill, Ronan; Campana, Juan Pablo; Candido, Fransesca di; Capolupo, Gabriella T.; Caricato, Marco; Caro-Tarragó, Aleidis; Casati, Massimiliano; Cassinotti, Elisa; Chadwick, Michael; Chitsabesan, Praminthra; Christoforidis, Dimitri; Coetzee, Emile; Coget, Julien; Collera, Pablo; Courtney, Edward; Cunningham, Chris; Dagbert, Francois; Dalton, Stephen J.; Damieta, Marta Pascual; Dapri, Giovanni; Dayal, Sanjeev; de Manzini Nicolo; de Pooter, Karl; DeLacy, Borja; Delgado, Salvadora; Dimitrov, Dobromir; Duff, Sarah; Dzhumabaev, Khasan Erkinovich; Edwards, Tom; Egenvall, Monika; Estevez-Schwarz, Lope; Færden, Arne E.; Faes, Seraina; Feleppa, Cosimo; Ferrero, Alessandro; Forsmo, Havard; Freitas, Christiano Denoni; Frontali, Alice; Gamage, Bawantha; García-Florez, Luis J.; Geissmann, Daniel; Glöckller, Markus; Gloor, Severin; Grolich, Tomas; Hahnloser, Dieter; Harikrishnan, Athur; Hasegawa, Hiro; Haunold, Ingrid; Hevia, Maria Fernandez; Hol, Jeroen; Horwood, James; Ial, Roshan; Ito, Masaaki; Julião, Guilherme Pagin São; Karamanliev, Martin; Killeen, Shane; Kneist, Werner; Kok, Siu Yan; Korsgen, Stephan; Kusters, Miranda; la Terra, Antonio; Lacy, Antonio; Lakatos, Lorand; Lambrecht, Jan R.; Lavik, Sigmund; Lee, Larence; Liberman, Sender A.; Lorenzon, Laura; Mackey, Paul; Mamedli, Zaman Zaur; Marcy, Tobias; Maroon, Tohmeh; Marti, Lukas; Massucco, Paolo; Mattacheo, Adrián Ezequiel; McCallum, lain; Meyer, Jeremy; Michalopoulos, Antonios; Mikalauskas, Saulius; Miroshnychenko, Yevgen; Mitermair, Christof; Moore, Tim; Mooslechner, Barbara; Morino, Mario; Muñoz C., Muratore, Andrea; Mutafchiyski, Ventsislav Metodiev; Myers, Alistair; Navarro, Joaquim; Nicol, Deborah; Nishizaki, Daisuke; Nolan, Gregory John; Ochsner, Alex; Oh, Jae Hwan; Osenda, Edoardo; Ourô, Susana; Panis, Yves; Papavramidis, Theodosios; Paraoan, Marius; Pastor, Carlos; Pei, Cherylin Fu Wan; Penchev, Dimitar; Pera, Miguel; Perdawood, Sharaf; Perez, Rodrigo Oliva; Persiani, Roberto; Pfeffer, Frank; Phang, P. Terry; Poskus, Eligijus; Ris, Frederic; Rockall, Timothy Alexander; Romero-Marcos, Juan Manuel; Roquete, Paulo; Rossi, Gustavo; Ruffo, Giacomo; Ruiz, Marcos Gomez; Sagar, Jayesh; Sakai, Yoshiharu; Sanchon, Lorena; Scala, Andrea; Schaap, Dennis; Scheiding, Monica Millan; Schiavo, Marcello; Schmidt, Eduardo Miguel; Sevá-Pereira, Gustavo; Sguinzi, Raffaella; Shalaby, Mostafa; Sharma, Abhiram; Shashank, Gurjar; Sietses, Colin; Sileri, Pierpaolo; Slesser, Alistair; Sohn, Dae Kyung; Solis-Peña, Alejandro;

Soravia, Claudio; Sosef, Meindert M.N.; Spinelli, Antonino; Storms P.; Studer, Peter; Syk, Erik; Talsma, Aaldert Konraad; Tejedor, Patricia; Temple, Sara; Tognelli, Joaquín; Tong, Weihua; Torkington, Jared; Tuech, Jean-Jacques;

Tzovaras, George; Van de Putte, Dirk; van Nieuwenhove, Yves; von Papen, Michael; Vorburger, Stephan; Wang, Quan; Warrier, Satish; Weiss, Helmut; Witzig, Jacques-Alain; Wolff, Torsten; Wynn, Greg; Zingg, Urs. 